\title{
Heuristic Portfolio Trading Rules with Capital Gain Taxes
}

\author{
Fischer, Marcel; Gallmeyer, Michael
}

Document Version

Accepted author manuscript

Published in:

Journal of Financial Economics

DOI:

10.1016/j.jfineco.2016.01.024

Publication date:

2016

\section{License \\ CC BY-NC-ND}

Citation for published version (APA):

Fischer, M., \& Gallmeyer, M. (2016). Heuristic Portfolio Trading Rules with Capital Gain Taxes. Journal of Financial Economics, 119(3), 611-625. https://doi.org/10.1016/j.jfineco.2016.01.024

Link to publication in CBS Research Portal

\section{General rights}

Copyright and moral rights for the publications made accessible in the public portal are retained by the authors and/or other copyright owners and it is a condition of accessing publications that users recognise and abide by the legal requirements associated with these rights.

Take down policy

If you believe that this document breaches copyright please contact us (research.lib@cbs.dk) providing details, and we will remove access to the work immediately and investigate your claim. 


\section{Heuristic Portfolio Trading Rules with Capital Gain Taxes Marcel Fischer and Michael Gallmeyer}

Journal article (Post print version)

Cite: Heuristic Portfolio Trading Rules with Capital Gain Taxes. / Fischer, Marcel; Gallmeyer, Michael. In: Journal of Financial Economics, Vol. 119, No. 3, 2016, p. 611-625

DOI: 10.1016/j.jfineco.2016.01.024

Uploaded to Research@CBS: May २०16

(2) 2016. This manuscript version is made available under the CC-BY-NC-ND 4.0 license http://creativecommons.org/licenses/by-nc-nd/4.0/ 


\title{
Heuristic Portfolio Trading Rules with Capital Gain Taxes ${ }^{\text {th }}$
}

\author{
Marcel Fischer ${ }^{1}$, Michael F. Gallmeyer ${ }^{2}$
}

\begin{abstract}
We study the out-of-sample performance of portfolio trading strategies when an investor faces capital gain taxation and proportional transaction costs. Overlaying simple tax trading heuristics on trading strategies improves out-of-sample performance. For medium to large transaction costs, no trading strategy can outperform a $1 / \mathrm{N}$ trading strategy augmented with a tax heuristic, not even the most tax- and transaction-cost efficient buy-and-hold strategy. Overall, the best strategy is $1 / \mathrm{N}$ augmented with a heuristic that allows for a fixed deviation in absolute portfolio weights. Our results thus show that the best trading strategies balance diversification considerations and tax considerations.
\end{abstract}

JEL classification: G11, H20

Keywords: portfolio choice, capital gain taxation, limited use of capital losses, heuristic trading rules

\section{Introduction}

While capital gain taxation is an important friction faced by individual investors, it is notoriously difficult to model. In particular, most capital gain taxation schemes are realization-based, implying taxes are only assessed when a trading position is closed.

\footnotetext{
We thank Yiorgos Allayannis, Rich Evans, Mary Margaret Frank, Burton Hollifield, Bjarne Astrup Jensen, Ralph Koijen, Marc Lipson, Hong Liu, Anthony Lynch, Spencer Martin, Claus Munk, Mads Stenbo Nielsen, Lasse Pedersen, G. William Schwert (the editor), Neal Stoughton, Frank Warnock, and seminar participants at Copenhagen Business School, the Darden School of Business, Goethe University Frankfurt, the Luxembourg School of Finance, the CREATES Symposium on Dynamic Asset Allocation at Aarhus University, the 11th Financial Markets Colloquium in Cologne, the 2012 German Finance Association Annual Meeting in Hannover, the 2013 Arne Ryde Workshop in Lund, and the 2014 McGill Risk Management Conference for comments. We are particularly indebted to an anonymous referee whose comments greatly improved our manuscript. Michael Gallmeyer acknowledges support from the McIntire Center for Financial Innovation. Marcel Fischer gratefully acknowledges financial support from the Danish Center for Accounting and Finance. All errors are our own.

Email addresses: marcel.fischer@uni.kn (Marcel Fischer), mgallmeyer@virginia.edu (Michael F. Gallmeyer)

${ }^{1}$ Corresponding author. Copenhagen Business School, Department of Finance, Solbjerg Plads 3, DK-2000 Frederiksberg, Denmark. Marcel Fischer is also affiliated with the University of Konstanz, Department of Economics, Postbox 147, D-78457 Konstanz, Germany, phone: +49 7531 882645, fax: +497531883559.

${ }^{2}$ University of Virginia, McIntire School of Commerce, Rouss \& Robertson Halls, East Lawn, Office 366, Charlottesville, Va 22904-4173, United States of America, phone: +1-434-243-4043.
} 
Furthermore, computing capital gain taxes typically involves tracking the past purchase prices of securities to correctly establish a position's tax basis. This combination makes solving for optimal portfolios especially problematic as the complexity of the problem faced is similar to solving a state-dependent transaction cost problem. Specifically, solving portfolio choice problems with a large number of stocks is especially vexing given that a large number of state variables beyond just stock holdings must be used to describe the problem. $3^{3}$

Progress has been made on how capital gain taxation influences optimal portfolio choice by studying less complex problems with simplifying assumptions. For example, the seminal work of Constantinides (1983) explores a setting where investors can effectively undo the effect of capital gain taxation by engaging in "shorting-against-the-box" trades when capital gains and losses are treated symmetrically. Later work has focused on settings more consistent with current tax codes where it is more difficult to circumvent capital gain taxes.

Given the complexity of incorporating a capital gain tax that cannot be circumvented, this later work relies on numerically solving portfolio choice problems by restricting the number of stocks considered as well as simplifying the evolution of each stock's tax basis by typically using an average purchase price basis rule. Dammon, Spatt, and Zhang (2001b) numerically study a stock and bond portfolio choice problem where the investor must potentially realize capital gains to rebalance for risk-return motives. Building from this paper, other works study even richer environments such as incorporating two risky stocks (Dammon, Spatt, and Zhang, 2001a; Garlappi, Naik, and Slive, 2001; Gallmeyer, Kaniel, and Tompaidis, 2006), the exact purchase price tax basis rule (DeMiguel and Uppal, 2005), separate taxable and tax-deferred accounts for the same investor (Dammon, Spatt, and Zhang, 2004; Garlappi and Huang, 2006; Huang, 2008), the limited use of

\footnotetext{
${ }^{3}$ Appendix C of Gallmeyer, Kaniel, and Tompaidis (2006) describes some of the computational issues related to just a two stock capital gain tax portfolio choice problem. In particular, they have to employ parallel computing techniques to solve a lifetime portfolio choice problem in a reasonable amount of time. See also Lo and Haugh (2001b) for a broader discussion of the computational problems faced when computing optimal portfolios.
} 
realized capital losses (Marekwica, 2012; Ehling, Gallmeyer, Srivastava, Tompaidis, and Yang, 2014), and wash-sale constraints (Jensen and Marekwica, 2011). This work, however, is not easily applicable to portfolios with a large number of stocks due to the well-known curse of dimensionality. This is the focus of our work where we attempt to develop heuristic trading rules that take capital gain taxation into account for several stocks, 4

In parallel to the work on portfolio choice with capital gain taxation, recent work such as DeMiguel, Garlappi, and Uppal (2009) stresses the importance of out-of-sample performance of portfolio choice rules in the presence of estimation risk. An out-of-sample analysis should be especially important in the context of capital gain taxation as out-ofsample performance is driven by how efficiently taxes are paid in addition to risk-return concerns. To explore the economic importance of tax-optimizing portfolio strategies, we build tax-optimized heuristic trading rules by modifying existing no-tax portfolio choice strategies and analyze their performance out-of-sample across a variety of data sets.

Our work has two goals. First, whereas Israel and Moskowitz $(2012)$ assess the aftertax performance of different equity styles, we want to understand how capital gain taxation and proportional trading costs influence the performance of portfolio strategies empirically that have been shown to perform well in a frictionless setting. Second, we want to understand how tax-optimized heuristic trading rules that modify existing strategies might perform better. Our work complements Bergstresser and Pontiff (2012) who study the after-tax performance of several style portfolios using historical tax rates where simple tax-minimization trades are implemented.

Our choice of heuristic tax trading strategies is motivated by the capital gain tax portfolio literature such as Dammon, Spatt, and Zhang (2004) and Gallmeyer, Kaniel, and Tompaidis (2006). In this literature, an investor trades off rebalancing a portfolio for risk-return incentives against the tax costs of rebalancing. We consider five heuristic

\footnotetext{
${ }^{4}$ Our work, by incorporating proportional transaction costs, also complements the literature on numerical portfolio choice work with transaction costs such as Balduzzi and Lynch (1999, 2000), Leland (2001), and Lynch and Tan (2010).
} 
trading strategies that differ in how they treat securities with unrealized gains. First, we consider two simple trading strategies that never realize capital gains or only realize gains when the investor is endowed with a sufficiently large tax loss from previous trading to avoid capital gains taxes. Next, we consider two strategies that introduce no-trade regions by allowing for relative or absolute deviations from the corresponding benchmark portfolio weights. Finally, we consider a trading strategy where the deviation of the benchmark portfolio weight depends on the level of the unrealized capital gain.

Overall, we find a role for tax-optimized heuristic trading rules to improve the performance of trading strategies out-of-sample. Reconfirming the results of DeMiguel, Garlappi, and Uppal (2009), we show that, under no capital gain taxation and no brokerage fees, a simple $1 / \mathrm{N}$ trading strategy is not dominated out-of-sample by a variety of optimizing trading strategies with the notable exception being the parametric portfolios of Brandt, Santa-Clara, and Valkanov (2009). Once capital gain taxes are imposed, the welfare cost of the tax is as large as $20 \%$ of wealth in some cases.

Overlaying simple tax trading heuristics on these trading strategies improves out-ofsample performance. In particular, the $1 / \mathrm{N}$ trading strategy's welfare gain improves with a variety of tax trading heuristics imposed. For medium to large trading costs, no trading strategy can outperform a $1 / \mathrm{N}$ trading strategy augmented with a tax heuristic, not even the most tax- and transaction cost efficient buy-and-hold strategy beats the heuristic allowing for no-trade regions around the benchmark portfolio weights. Overall, the best strategy is $1 / \mathrm{N}$ augmented with the heuristic allowing for no-trade regions around the benchmark portfolio weights. Welfare gains from using this heuristic compared to the non-augmented $1 / \mathrm{N}$ strategy can be as large as $6.41 \%$ of the investor's initial wealth. Our results thus show that the best trading strategies trade diversification considerations off against tax considerations without solely focusing on one or the other.

The paper proceeds as follows. Section 2 introduces the portfolio strategies considered and explores their performance in a no tax setting. Section 3 imposes a capital gain tax and asks how the out-of-sample performance of the trading strategies are impacted. Tax 
trading heuristics that augment the portfolio strategies are explored in Section 4 . Section 5 concludes. Additional details on the construction of our out-of-sample portfolios are provided in the Appendix.

\section{Trading Strategy Efficiency under No Taxation}

Before turning to how capital gain taxation impacts out-of-sample portfolio performance, we first establish a benchmark set of portfolio choice strategies. These strategies have been previously studied in an out-of-sample context with no market imperfections. The data sets used to test out-of-sample performance for an investor maximizing utility over terminal wealth with a $T$ month investment horizon are also described.

The investor's preferences are CRRA expected utility from terminal wealth $W$ with a relative risk aversion coefficient $\gamma$. That is, the investor's utility is given by

$$
U(W)= \begin{cases}\frac{W^{1-\gamma}}{1-\gamma} & \text { if } \gamma \neq 1 \\ \ln (W) & \text { if } \gamma=1\end{cases}
$$

To maximize utility, the investor chooses an allocation in $N$ risky stocks each month. The vector of portfolio weights is denoted $\mathbf{w}_{t}$. Individual portfolio weights are referred to as $w_{1, t}, \ldots, w_{N, t}$.

\subsection{Portfolio Choice Strategies}

Our candidate benchmark portfolio strategies are chosen from past work such as Jagannathan and Ma (2003), Brandt, Santa-Clara, and Valkanov (2009), and DeMiguel, Garlappi, and Uppal (2009). Given our objective to study portfolios that could be implemented by individual investors, we do not explicitly focus on strategies with short selling. Given we compute certainty equivalents for a CRRA investor, he is never willing to accept a wealth profile with the possibility of a negative terminal wealth. Below we outline the portfolio choice strategies we consider which are summarized in Table 1. 

nathan and $\mathrm{Ma}(2003)$

Parametric portfolio as in Brandt, Santa-Clara, and Valkanov (2009) using the factors Size, Book-to-Market, and Momentum with the valueweighted market portfolio as initial portfolio weights

Parametric portfolio as in Brandt, Santa-Clara, and Valkanov (2009) using the factors Size, Book-to-Market, and Momentum with the equallyweighted market portfolio as initial portfolio weights

Table 1: Portfolio Strategies Considered.

\section{$1 / N$ Strategy $(1 / N)$}

DeMiguel, Garlappi, and Uppal (2009) evaluate fourteen different portfolio choice models across seven data sets and show that none of those portfolio choice models performs consistently better in terms of Sharpe ratios, certainty equivalent returns, or turnover as compared to $1 / \mathrm{N}$. They argue that potential diversification gains from more advanced portfolio choice strategies are outweighed by estimation error. The naïve diversification strategy of holding an equal share of wealth in all stocks at each and every point in time defines our $1 / \mathrm{N}$ strategy. From a tax perspective, a $1 / \mathrm{N}$ investor tends to incur capital gain tax costs as winners are sold and losers are bought to adjust portfolio weights back to $1 / \mathrm{N}$.

\section{Value-Weighted Market Portfolio Strategy (VW)}

The only portfolio all investors could hold at the same time that would lead to market clearing is the value-weighted market portfolio. For the value-weighted market portfolio, the share of the investor's wealth held in each stock is equal to the fraction of the stock's market value to the total market value of all stocks considered. Any dividends paid 
are reinvested to preserve value-weighting. We refer to this benchmark portfolio choice strategy as VW throughout.5

\section{Buy-and-Hold Strategy (BH)}

From a capital gain tax perspective, a buy-and-hold strategy is an obvious strategy to employ to help minimize tax trading costs. It is also particularly easy to implement given no rebalancing is necessary. Past research such as Lo and Haugh (2001a) and Rogers (2001) shows that buy-and-hold strategies perform well relative to fully-optimized dynamic portfolio strategies. Additionally, the results in the appendix to DeMiguel, Garlappi, and Uppal (2009) (DeMiguel, Garlappi, and Uppal, 2006) suggest that the buyand-hold strategy initially invested in the $1 / \mathrm{N}$ portfolio might result in a slightly higher certainty equivalent return than the $1 / \mathrm{N}$ portfolio strategy with rebalancing. Our buyand-hold strategy, denoted $\mathrm{BH}$, therefore initially invests in the $1 / \mathrm{N}$ portfolio and does not rebalance portfolio weights during the entire investment horizon except to reinvest dividends back into the paying stocks. We also consider the case where dividends are reinvested to rebalance the portfolio when we study tax heuristics in Section 4. The other benchmark models we consider solely focus on the risk-return tradeoff and ignore tax effects, whereas BH can be thought of as the other extreme. It solely focuses on deferring capital gain taxes and ignores dynamic risk-return considerations.

\section{Short Sale Constrained Minimum Variance Strategy (MV)}

Moving beyond the $1 / \mathrm{N}$, the VW, and the $\mathrm{BH}$ strategies requires the estimation of return statistics. One of the simplest portfolio strategies to implement both in computation and in estimation is a minimum variance portfolio. From Markowitz (1952), optimal portfolio weights are the solution to a simply quadratic programming problem that can be solved for a large number of stocks. The only quantity to estimate is the return variance-covariance matrix. Solving for other points on the mean-variance frontier is not considered here as estimation errors in mean returns have a substantial impact on

\footnotetext{
${ }^{5}$ Given that the value-weighted market portfolio is generally dominated by the equally-weighted portfolio, we do not report these results here. They are available in our online appendix.
} 
estimated portfolio weights (Best and Grauer, 1991; Green and Hollifield, 1992; Chopra and Ziemba, 1993).

In our strategy denoted MV, portfolio weights at time $t$ are found by solving

$$
\arg \min _{\mathbf{w}} \mathbf{w}_{t}^{\top} \Sigma_{t} \mathbf{w}_{t} \quad \text { s.t. } \quad \mathbf{1}^{\top} \mathbf{w}_{t}=1, \quad w_{i, t} \geq 0
$$

where $\Sigma_{t}$ denotes the variance-covariance matrix of returns and $\mathbf{1}$ denotes a vector of ones. Portfolio weights are short-sale constrained as Jagannathan and Ma (2003) show that constraints can help improving out-of-sample performance.

\section{Parametric Portfolio Strategies (PPVW and PPN)}

Work by Brandt, Santa-Clara, and Valkanov (2009) suggests modeling portfolio weights as a function of stock-specific characteristics such as size, book-to-market, and momentum. Estimating portfolio weights directly from stock-specific characteristics helps alleviate estimation errors, as stock return moments are not directly estimated leading to improved out-of-sample performance. In contrast to the other benchmark portfolio strategies considered, the parametric portfolios are utility maximizing and take investor preferences explicitly into account.

The Brandt, Santa-Clara, and Valkanov (2009) parametric portfolios are constructed by assuming that the portfolio weight of stock $i$ at time $t, w_{i, t}$, can be expressed as a function of that stock's characteristics at time $t, x_{i, t}$. This is given by $w_{i, t}=f\left(x_{i, t} ; \theta\right)$. The function $f(\cdot)$ is common across all stocks and time. The vector $\theta$ parameterizes $f(\cdot)$. We again constrain the investor's portfolio weights to be non-negative. After computing unconstrained portfolio weights $w_{i, t}$, we adjust them as follows:

$$
w_{i, t}^{+}=\frac{\max \left[w_{i, t}, 0\right]}{\sum_{j=1}^{N} \max \left[w_{j, t}, 0\right]}=\frac{\max \left[f\left(x_{i, t}, \theta\right), 0\right]}{\sum_{j=1}^{N} \max \left[f\left(x_{j, t}, \theta\right), 0\right]} .
$$

Maximizing utility from the gross portfolio return from time $t$ to time $t+1$ is then equivalent to the optimization problem $\max _{\theta} \mathbb{E}\left[U\left(\sum_{i=1}^{N} w_{i, t}^{+} R_{i, t}\right)\right]$ where $R_{i, t}$ is the gross 
return on stock $i$ from time $t$ to $t+1 \sqrt[6]{6}$

To apply the parametric portfolio approach, we must specify the stocks' characteristics and the function $f(\cdot)$. Following Brandt, Santa-Clara, and Valkanov (2009), we use the log of the stocks' market equity, the log of one plus book equity divided by market equity, and the lagged one-year return from time $t-13$ to time $t-1$ as the stocks' characteristics. For $f(\cdot)$, an affine form is assumed:

$$
f\left(\hat{x}_{i, t}, \theta\right)=w_{i, t}=\bar{w}_{i, t}+\frac{1}{N} \theta^{\top} \hat{x}_{i, t},
$$

where $\bar{w}_{i, t}$ denotes an exogenously-specified initial portfolio weight. The vector $\hat{x}_{i, t}$ contains the characteristics of stock $i$ standardized cross-sectionally across stocks at time $t$ to have zero means and unit standard deviations.

Combining equations (3) and (4), the non-negative portfolio weights are given by

$$
w_{i, t}^{+}=\frac{\max \left[\bar{w}_{i, t}+\frac{1}{N} \theta^{\top} \hat{x}_{i, t}, 0\right]}{\sum_{j=1}^{N} \max \left[\bar{w}_{j, t}+\frac{1}{N} \theta^{\top} \hat{x}_{j, t}, 0\right]} .
$$

The vector $\theta$, based on an estimation window of length $M$, is chosen to maximize the investor's utility:

$$
\max _{\theta} \frac{1}{M} \sum_{m=1}^{M} U\left(\sum_{i=1}^{N} \frac{\max \left[\bar{w}_{i, m}+\frac{1}{N} \theta^{\top} \hat{x}_{i, m}, 0\right]}{\sum_{j=1}^{N} \max \left[\bar{w}_{j, m}+\frac{1}{N} \theta^{\top} \hat{x}_{j, m}, 0\right]} R_{i, m}\right) .
$$

Two different choices for the initial portfolio weights $\bar{w}_{i, t}$ are considered. First, following Brandt, Santa-Clara, and Valkanov (2009), we use the value-weighted market portfolio as the initial portfolio, denoted as the PPVW strategy. Second, we choose the $1 / \mathrm{N}$ portfolio as our initial portfolio, denoted as the PPN strategy. Due to space considerations, we only present results for the PPN strategy as the PPVW strategy results are similar.7

\footnotetext{
${ }^{6}$ We also explored an extension of the parametric portfolio strategy that optimizes a multi-period objective function. This strategy is not able to systematically outperform results obtained using the single-period objective function proposed in Brandt, Santa-Clara, and Valkanov (2009). Results for the multi-period objective function are available in our online appendix.

${ }^{7}$ The PPVW strategy results are available in our online appendix.
} 
In their work, Brandt, Santa-Clara, and Valkanov (2009) focus on a frictionless setting with no taxes and transaction costs. Our goal, however, is to study optimal portfolio strategies for individual investors in the presence of taxes and transaction costs. Gârleanu and Pedersen (2013) show that in the presence of trading costs, optimal portfolio strategies only trade partially toward the aim to reduce the transaction costs burden. We therefore model portfolio weights $\widehat{w}_{i, t}$ as:

$$
\widehat{w}_{i, t}=z \cdot \bar{w}_{i, t}+(1-z) w_{i, t}^{+}
$$

where $z \in[0,1]$ is a shrinkage factor that determines the extent of shrinkage. Empirically, a shrinkage factor of $z=0.5$ leads to an improved out-of-sample performance. Results reported for the PPN strategy throughout are therefore for $z=0.58$

\subsection{Data}

To evaluate portfolio strategies out-of-sample requires return data for a set of assets. Given that the focus of our work is on providing guidance to individual investors' portfolio decisions, it is important to consider menus of assets that individual investors can trade easily. We therefore consider two types of data sets: (1) Mutual funds/exchange traded funds (ETFs) and (2) individual stocks. The mutual fund data is taken from the CRSP Mutual Fund Database. Two sets of mutual funds are considered which are meant to proxy for industry and style portfolios.

The CRSP Mutual Fund Database begins in 1962. It contains detailed information on mutual fund returns, distributed dividends, and capital gains. These are needed to determine after-tax mutual fund returns. It also contains information on mutual fund loads. However, these loads are typically so high that investors should not trade these funds frequently. More recently, ETFs have become an attractive alternative to traditional mutual funds. In particular, ETFs can typically be traded by individual investors at low trading costs. In our setting where portfolios are adjusted on a monthly basis,

\footnotetext{
${ }^{8}$ Results for other choices of $z$ are available in our online appendix.
} 
investors should prefer ETFs to traditional mutual funds from a trading cost perspective.

Ideally, we should then use ETFs instead of mutual funds in our analysis. However, ETFs are a more recent financial innovation. Given the goal of our work to explore the long-term consequences of capital gain taxation, the time series of observed ETF returns is too short to generate a reasonable number of out-of-sample observations. We therefore proxy for ETF returns using mutual fund returns and calibrate spreads for trading ETFs based on existing ETFs. To maximize the number of observations, we focus on mutual funds from those 5 industries in the cleaned CRSP Mutual Fund Database that range back to 19629 We refer to this data set as INMF throughout. For our style mutual funds, we randomly choose one large-cap, one mid-cap, one small-cap, one growth, and one income mutual fund from the menu of funds available in 1962. Given that these funds proxy for Fama-French portfolios, we refer to this data set as FFMF throughout.

We also consider direct stock investments. More specifically, we consider 10 randomly chosen stocks from the CRSP/Compustat merged database and refer to this data set as CRSP throughout. ${ }^{10}$ Exploring a data set with individual stocks is also important given the empirical evidence in Ravina, Viceira, and Walter (2011) that high net worth U.S. households prefer trading individual stocks for tax reasons. To avoid survivorship bias, we allow for stocks to be delisted from our randomly chosen stocks. Each delisted stock is replaced by randomly choosing a new stock at the time of delisting. All the data sets used, including the time period used to build the out-of-sample returns, are summarized in Table 2,

In addition to return data, the parametric portfolio choice strategies require data on book-to-market ratios and market capitalization. For the CRSP data set, we follow Brandt, Santa-Clara, and Valkanov (2009) in constructing these factors. A detailed description of the selection process of the 10 randomly selected stocks from the CRSP database and the computation of the factors book-to-market and size for those stocks is

\footnotetext{
${ }^{9}$ The technical details of the data cleaning process are described in Appendix A

${ }^{10} \mathrm{We}$ also explored cases with up to 30 assets. Results for these cases are similar to those reported here and are available in our online appendix .
} 


\begin{tabular}{lccll} 
Data set & Abbreviation & Observations & Source \\
\hline $\begin{array}{l}5 \quad \text { industry } \\
\text { funds }\end{array}$ & mutual & INMF & $01 / 1974-12 / 2012$ & CRSP Mutual Fund Database \\
5 style mutual funds & FFMF & $01 / 1974-12 / 2012$ & CRSP Mutual Fund Database \\
$\begin{array}{l}10 \text { randomly chosen } \\
\text { stocks }\end{array}$ & CRSP & $01 / 1963-12 / 2012$ & $\begin{array}{l}\text { CRSP/Compustat } \\
\text { database }\end{array}$ & merged \\
\hline \hline
\end{tabular}

Table 2: Data Sets Used

given in Appendix A. For all data sets, we construct the time series for the momentum factor as the lagged compounded one-year return from time $t-13$ to $t-1$. For the CRSP data set, we use the log of 1 plus the book-to-market ratio, the log of firm size, and the momentum factor as the stocks' characteristics in the parametric portfolio approach. For the mutual fund portfolios, data on the book-to-market ratio and the sizes of the assets held by the funds is not available in the CRSP mutual fund database. For this data set, investors only use the momentum factor as the assets' characteristics in the parametric portfolio approach.

To assess out-of-sample performance, our computations rely on a "rolling-sample" approach where the length of our data set is assumed to be $J$ monthly observations. We use $M$ months of data to estimate parameters needed to form portfolios. Beginning at time $t=M+1$ to $t=M+T$, we estimate portfolio weights at each of those points in time for the past $M$ months of data. Given our goal to determine portfolio strategies that perform well after taking taxes into account, we use after-tax returns in the process of estimating portfolio weights. That is, we explicitly account for the taxation of dividends and the capital gain tax consequences of trading inside mutual funds 11 We compute the pre-tax portfolio return for each period. Using these portfolio weights and returns, we compute the investor's final wealth at the end of the investment horizon. We then increase the beginning and the end of the investment horizon successively by one period until we

\footnotetext{
${ }^{11}$ We also explored a setting where the mutual fund imposed no capital gains tax burden on the investor. The results are essentially identical to those reported here and are available in our online appendix.
} 
reach the end of our data set. By doing so, we generate a series of $J-M-T+1$ outof-sample observations for the investor's terminal wealth. Based on these out-of-sample observations of terminal wealth $W$, we compute the expected realized utility $E U$ :

$$
E U=\frac{1}{1-\gamma} \mathbb{E}\left[W^{1-\gamma}\right]
$$

and the corresponding certainty equivalent $C E Q$ as:

$$
C E Q=((1-\gamma) E U)^{1 /(1-\gamma)}
$$

\subsection{Investor Characteristics and Transaction Costs}

We first analyze the performance of our portfolio choice strategies in a setting with no taxation. Unless otherwise stated, we consider an investor with a relative risk aversion of $\gamma=5$ and an investment horizon of $T=120$ months. ${ }^{12}$ The investor uses $M=$ 120 months of historical data to estimate parameters for determining current portfolio weights.

We also incorporate proportional transaction costs into our analysis to capture how the trading costs impact the performance of each strategy. Transaction costs faced by individual investors generally consist of two components: (1) the spread and (2) a commission payable to the investor's broker. Spreads typically vary between assets and tend to be higher for less liquid assets with lower market capitalizations. Also, spreads have generally been declining over the past decades. For the CRSP data set, we estimate each assets' spread as the average spread reported over the most recent 5 years. Given that spreads for ETFs are not reported in the CRSP Mutual Fund Database, spreads for the INMF and the FFMF data set are calibrated based on existing ETF spreads. We refer to Appendix A for details about this estimation procedure. We assume the fundamental value of an asset to correspond to its midpoint price, implying that half the spread

\footnotetext{
${ }^{12}$ We also explored the robustness of our findings by varying the risk aversion and the investment horizon length. Given that our key findings are robust to these variations, we only report them in our online appendix.
} 
constitutes a trading cost for the investor.

For the commission payable to the broker, we consider three different levels of proportional transaction costs: 0\%, 0.5\% (50 basis points), and 1\% (100 basis points). The zero fee cost case is meant to isolate the impact of each strategy by itself. The proportional fees of 50 and 100 basis points are at levels that individual investors may face. They are also in the range of values estimated by Lesmond, Ogden, and Trzcinka (1999) and those used in Lynch and Tan (2010). In all cases considered, the investor always faces the bid-ask spread. The different levels of transaction costs considered capture the impact of different brokerage fees.

\subsection{Results under No Taxation}

Under no taxation and brokerage fees, Table 3 summarizes certainty equivalent gains relative to the $1 / \mathrm{N}$ strategy (Panel A) and trading volume (Panel B) for the strategies considered. Before discussing the results, it is useful to describe how the summary statistics in the table are computed.

In Panel $\mathrm{A}$, the certainty equivalent gain $C E Q_{G}$ relative to the $1 / \mathrm{N}$ strategy is defined as the difference between the investor's certainty equivalent under each benchmark portfolio choice strategy $C E Q_{B M}$ and the $1 / \mathrm{N}$ benchmark portfolio strategy $C E Q_{N}$ divided by the certainty equivalent under the $1 / \mathrm{N}$ benchmark portfolio strategy:

$$
C E Q_{G}=\frac{C E Q_{B M}-C E Q_{N}}{C E Q_{N}}
$$

For example, the PPN trading strategy under the CRSP data set has a certainty equivalent increase of $3.23 \%$ implying that a $1 / \mathrm{N}$ investor's wealth would have to increase by that percentage to be just as well off as under the PPN trading strategy. To assess the statistical significance of the certainty equivalent gains, we construct a test statistic to test the null hypothesis that the certainty equivalent gain is non-positive. Given the large degree of overlap of the investment horizons, assessing the statistical significance of the certainty equivalent gain using asymptotic statistics is problematic. To account for the 
serial dependence in the data, we use a parametric bootstrap instead ${ }^{13}$

More specifically, we proceed in five steps:

- First, a portfolio strategy results in a positive certainty equivalent gain relative to the $1 / \mathrm{N}$ strategy if and only if the utility level under that strategy is higher than under the $1 / \mathrm{N}$ strategy. Hence, for computing p-values, it is sufficient to compare utility levels with each other. Given that adjusting standard errors for serial correlation with a Newey-West adjustment is straightforward based on utility levels, but challenging based on certainty equivalent gains, we follow Lan (2014) and compute p-values based on utility levels.

- Second, we estimate a vector autoregressive model (VAR) for capital gains, dividends, tax burdens passed on to fund holders, and the fundamental data used in the parametric portfolios (momentum, size and, book-to-market). Specifically, we estimate a $\operatorname{VAR}(1)$. That is, when $\mathbf{y}_{t}$ denotes a vector of capital gains, dividends, and tax burdens imposed through period $t$ and fundamental data at the beginning of period $t$, we estimate a vector of parameters $\Gamma$ using the OLS in the regression

$$
\mathbf{y}_{t}=\Gamma \mathbf{y}_{t-1}+\epsilon_{t}
$$

Based on these parameter estimates and standard normally distributed random variables, we generate $B$ samples of capital gains, dividends, tax burdens, and fundamental data. Each sample's initial values are set to a randomly drawn set of observations from the true data. Negative observations for VAR-generated dividends or tax burdens are set to zero.

- Third, we compute the out-of-sample performance for all our benchmark portfolio strategies on each bootstrap sample. We compute our bootstraps under the null

\footnotetext{
${ }^{13}$ In our CRSP data set, some time series terminate due to mergers and acquisitions or compensations in cash, which complicates the use of a block bootstrap. Yet, it is important to account for these events in our bootstraps. We therefore implement a parametric bootstrap, where we calibrate the probabilities of such events from the empirical data.
} 
that the levels of expected utility of the $1 / \mathrm{N}$ strategy and any other benchmark portfolio strategy are identical. We therefore scale the bootstrapped levels of total final wealth by $C E Q_{N} / C E Q_{B M}$ for each benchmark portfolio strategy considered.

- Fourth, we compute the realized utility gains $U G^{b}=U_{B M}^{b}-U_{N}^{b}$ for each bootstrap $b$ and all benchmark portfolio strategies considered.

- Finally, we compute the p-values as the percentage of bootstrap samples for which

$$
\frac{U G^{b}}{\sigma\left(U G^{b}\right)}>\frac{U G}{\sigma(U G)}
$$

where $U G=U_{B M}-U_{N}$ is the utility gain in the empirically observed data and $\sigma(U G)$ and $\sigma\left(U G^{b}\right)$ are the GMM-based asymptotic standard errors of $U G$ and $U G^{b}$, adjusted for serial correlation with a Newey-West adjustment of order $T-1$. P-values reported throughout are computed accordingly.

Since every bootstrap involves several hundred portfolio optimizations and keeping track of a larger number of tax bases and portfolio positions, this bootstrap procedure is very time-consuming. To expedite computations, we employ parallel computing. Nevertheless, we have to restrict ourselves to $B=1,000$ bootstraps.

For trading strategy $i$, let $w_{j, t, o b s}^{i}$ denote the portfolio weight of stock $j$ at the beginning of the $t$-th month of the investment horizon in the out-of-sample observation obs after trading has occurred. The weight $w_{j, t-, o b s}^{i}$ is the corresponding portfolio weight before trading at time $t$. The average trading volume over all out-of-sample observations for trading strategy $i$ is defined as

$$
\text { Trading volume }{ }^{i}=\frac{1}{Y \cdot(T-1)} \sum_{o b s=1}^{Y} \sum_{t=2}^{T} \sum_{j=1}^{N}\left|w_{j, t, o b s}^{i}-w_{j, t-, o b s}^{i}\right| .
$$

To not bias the reported trading volumes, initial trades to establish the portfolio as well as final trades to liquidate the portfolio are not included.

Turning to our results, Panel A of Table 3 reports certainty equivalent gains of our 
Panel A: Gain Relative to 1/N

\begin{tabular}{lrrr} 
Data & MV & BH & PPN \\
\hline \hline FFMF & -6.03 & 1.47 & 0.66 \\
& $(0.85)$ & $(0.26)$ & $(0.36)$ \\
INMF & -18.95 & -1.65 & 1.10 \\
& $(0.93)$ & $(0.68)$ & $(0.31)$ \\
CRSP & -0.60 & -11.12 & 3.23 \\
& $(0.57)$ & $(1.00)$ & $(0.00)$ \\
\hline \hline
\end{tabular}

Panel B: Trading Volume

\begin{tabular}{lllrr} 
Data & $1 / \mathrm{N}$ & $\mathrm{MV}$ & $\mathrm{BH}$ & $\mathrm{PPN}$ \\
\hline \hline FFMF & 2.08 & 1.63 & 0.69 & 12.61 \\
INMF & 3.76 & 3.87 & 0.68 & 9.80 \\
CRSP & 5.13 & 5.59 & 0.47 & 17.40 \\
\hline \hline
\end{tabular}

Table 3: Optimal Portfolio Performance under No Taxes. This table summarizes optimal portfolio performance under no taxes when brokerage fees are $\tau_{t}=0 \%$. Panel A reports the certainty equivalent gain in percent of initial wealth an investor earns on a particular strategy relative to the $1 / \mathrm{N}$ strategy. The values in parenthesis are p-values from 1000 bootstraps under the null hypothesis that the certainty equivalent gain is non-positive. Panel B reports the average trading volume as a percent of wealth under each strategy.

portfolio choice strategies relative to the $1 / \mathrm{N}$ portfolio choice strategy when no taxes and brokerage fees apply. Here investors just face a bid/ask spread. We refer to this case as the no fee case throughout. We use the $1 / \mathrm{N}$ strategy as our benchmark to compare with the other strategies given DeMiguel, Garlappi, and Uppal (2009) report that it is difficult to find portfolio choice strategies that systematically outperform it. Confirming their findings, our results show that the short sale constrained minimum variance (MV) and the buy-and-hold (BH) strategies do not outperform 1/N systematically out of sample. In fact, MV exhibits especially poor performance as $1 / \mathrm{N}$ dominates for all data sets. However, our results suggest that the parametric portfolio strategy with $1 / \mathrm{N}$ as initial portfolio weights (PPN) does systematically outperform the $1 / \mathrm{N}$ portfolio choice strategy. All reported utility gains are positive relative to $1 / \mathrm{N}$.

Panel B reports the average monthly trading volume under each portfolio choice strategy. Not surprisingly, the PPN portfolios have substantially higher trading volumes compared to the other strategies. Trading volume of all portfolios, including the buy-and-hold portfolio (BH), are impacted by dividend payments, seasoned equity offerings, mergers, 
Gains relative to 1/N, 50 Basis Points

\begin{tabular}{lrrr} 
Data & MV & BH & PPN \\
\hline \hline FFMF & -5.37 & 2.24 & -4.45 \\
& $(0.83)$ & $(0.21)$ & $(0.94)$ \\
INMF & -18.83 & 0.27 & -2.74 \\
& $(0.92)$ & $(0.53)$ & $(0.79)$ \\
CRSP & -0.96 & -8.73 & -3.79 \\
& $(0.64)$ & $(1.00)$ & $(0.98)$ \\
\hline \hline
\end{tabular}

Gains relative to $1 / \mathrm{N}, 100$ Basis Points

\begin{tabular}{lrrr} 
Data & MV & BH & PPN \\
\hline \hline FFMF & -4.71 & 3.00 & -9.31 \\
& $(0.82)$ & $(0.20)$ & $(0.93)$ \\
INMF & -18.70 & 2.22 & -6.49 \\
& $(0.92)$ & $(0.29)$ & $(0.89)$ \\
CRSP & -1.31 & -6.28 & -10.51 \\
& $(0.70)$ & $(1.00)$ & $(1.00)$ \\
\hline \hline
\end{tabular}

Table 4: Optimal Portfolio Performance under No Taxes with Transaction Costs. The values in parenthesis are p-values from 1,000 bootstraps under the null hypothesis that the certainty equivalent gain is non-positive.

acquisitions, and stocks exiting the data set. For those reasons, the trading volume is not zero even for the buy-and-hold portfolio $(\mathrm{BH})$.

Table 3 presented results when there are no transaction costs. From the large trading volume for the PPN strategy in Panel B, such fees could significantly impact the performance of this strategy. Table 4 presents certainty equivalent gains relative to the $1 / \mathrm{N}$ portfolio strategy when a proportional transaction fee of 50 (Panel A) and 100 basis points (Panel B) is imposed. Imposing a trading cost now impacts the performance of each trading strategy relative to $1 / \mathrm{N}$. In particular the performance gain of the PPN strategy relative to $1 / \mathrm{N}$ disappears once fees are imposed as seen in Table 4 . The 50 and 100 basis point fee cases also highlight the viability of the buy-and-hold strategy BH relative to $1 / \mathrm{N}$. With the increase in trading costs, the $\mathrm{BH}$ strategy now dominates the $1 / \mathrm{N}$ strategy for all data sets except the CRSP data set. 


\section{Trading Strategy Efficiency under Capital Gain Taxation}

We now explore how each of the trading strategies from the previous section behaves once a capital gain tax is imposed.

\subsection{Capital Gain and Dividend Taxation}

We focus on the realization-based feature of capital gain taxation; namely, that capital gain taxes are only paid when a position in a particular security is reduced. Dividends are assumed to be taxed once they are paid out. We abstract away from the rate of capital gain taxation being a function of the holding period. In particular, we assume that there is a single capital gain tax rate $\tau_{g}$ which is assessed portfolio-wide across all realized gains 14 Realized capital losses are either used to offset against current realized gains or carried forward as described below.

A variety of methods exist in world tax codes to determine the tax basis, or the price used to subtract from the current price when computing realized capital gains or losses. We consider three methods - a weighted-average purchase price rule, an exact identification rule, and an accrual-based method ${ }^{15}$ For space considerations, we only report results for the exact identification rule ${ }^{16}$ The weighted-average purchase price rule constructs the tax basis for a particular stock based on past purchase prices weighted by the number of shares purchased. It is commonly used in work that studies optimal portfolio choice under capital gain taxation numerically as it greatly reduces the dimensionality of the state space needed to describe the optimization problem. See for example Dammon, Spatt, and Zhang (2001b). The exact identification rule computes the tax basis by always reducing the position in a particular stock using the shares that

\footnotetext{
${ }^{14}$ Many capital gain tax codes impose different tax rates based on the holding period of a particular asset. For an analysis of long-term and short-term capital gain taxes in the U.S., see for example Dammon and Spatt (1996). We also studied settings where we set the capital gains rate to levels roughly corresponding to the U.S. long- and short-term capital gains rates. Given that our key results are not affected by these modifications, we only report results for a capital gains rate of $\tau_{g}=20 \%$ in this manuscript. Results for the cases $\tau_{g}=15 \%$ and $\tau_{g}=35 \%$ are available in our online appendix.

${ }^{15}$ The U.S. tax code allows for a choice between the weighted-average purchase price rule and the exact identification rule of the shares to be sold. The Canadian tax code uses the weighted-average purchase price rule.

${ }^{16}$ Results for the other two methods are available in our online appendix.
} 
lead to the smallest realized capital gain. DeMiguel and Uppal (2005) study the welfare benefits of the exact identification rule versus the weighted-average purchase price rule. The accrual-based method simply assumes that each trading period all capital gains and losses are realized.

Each month, the portfolio under each strategy is rebalanced to its optimal no tax allocation. In line with previous research on portfolio choice with taxes such as Dammon, Spatt, and Zhang (2004) and Gallmeyer, Kaniel, and Tompaidis (2006) and acknowledging that in practice wash sale restrictions can typically easily be circumvented, we do not impose such restrictions on the portfolio choice decision. So, positions in securities with realized capital losses can be immediately re-established. Consistent with most tax codes, we assume the limited use of capital losses implying that realized capital losses can only be used to offset realized gains now or in the future implying that unused capital losses must be tracked over the portfolio's life. This more realistic feature of the tax code has been studied in a no-arbitrage context by Gallmeyer and Srivastava (2011) and an optimal portfolio choice context by Marekwica (2012) and Ehling, Gallmeyer, Srivastava, Tompaidis, and Yang (2014).

One complication is how to handle the realization of capital losses. With no transaction costs, Gallmeyer and Srivastava (2011) and Marekwica (2012) show that it is weakly optimal for an investor to always realize all capital losses even if they cannot be immediately used to offset realized capital gains as these losses can be carried forward. With a proportional transaction cost, this result breaks down given the desire to also minimize transaction costs. We only realize losses when the present tax savings dominates the transaction cost incurred when realizing the loss $\sqrt{17}$ The exact procedure used for realizing losses is outlined in Appendix B.

For the tax treatment of the final trades to liquidate the portfolio at the end of the investment horizon, we consider two different cases. First, we consider the case where

\footnotetext{
${ }^{17}$ We also explored the consequences of realizing losses immediately when present and potential future tax savings exceed present transaction costs. These results results as well as documentation on a strategy that only realizes losses at the end of the investment horizon is available in our online appendix.
} 
total final wealth after the final trades is measured gross of capital gains taxes. That is, if $W_{T}$ denotes terminal wealth after transaction costs from liquidating trades, total final wealth after accounting for taxes is:

$$
W_{T}^{a}=W_{T}
$$

This case is relevant if the portfolio is inherited by the investor's descendants and capital gains are forgiven at death, such as under current US tax law. Second, we consider the case where total final wealth is measured net of capital gains. That is, if $\mathbf{s}_{T}$ is a vector of shares of wealth held in different positions, $\mathbf{p}_{T}$ is a vector of the corresponding basis-toprice ratios, and $L_{T} \leq 0$ is a tax loss remaining from previous trading, total final wealth after accounting for taxes is:

$$
W_{T}^{a}=W_{T}-\max \left(W_{T} \cdot \sum_{i=1}^{N} \mathbf{s}_{T, i} \cdot\left(1-\mathbf{p}_{T, i}\right)+L_{T}, 0\right) \tau_{g}
$$

This case is relevant when the investor survives and the value of the portfolio is consumed.

Throughout, dividends are taxed at a rate of $\tau_{d}=35 \%$. Realized capital gains are taxed at a rate of $\tau_{g}=20 \%$. While this rate is higher than the current U.S. rate of $\tau_{g}=15 \%$, it is more consistent with historical U.S. capital gain tax rates as well as tax rates in several European countries ${ }^{18}$ For a comprehensive summary of U.S. capital gain tax rates through time, see Figure 1 in Sialm (2009).

\subsection{Results under Capital Gain Taxation}

The out-of-sample performance of each portfolio choice strategy is summarized in Tables 5 and 6 where taxation is now introduced. Each table presents results for a 0 basis point (Panel A), a 50 basis point (Panel B), and a 100 basis point transaction cost (Panel C). In each table, the left panels consider the case when capital gain taxes

\footnotetext{
${ }^{18} \mathrm{We}$ also explored settings where we set the capital gains rate to $\tau_{g}=15 \%$ and where we set it to the dividend rate, i.e., where $\tau_{d}=\tau_{g}=35 \%$. Given that these modifications only affect our results quantitatively, but not qualitatively, we only report them in our online appendix.
} 
are forgiven at the end of the investment horizon, while the right panels consider the case when capital gain taxes are paid at the end of the investment horizon. Table 5 computes the certainty equivalent wealth loss for a particular strategy relative to the no-tax performance of that strategy. Hence, this table summarizes how costly it is for an investor to face taxation under each of the benchmark portfolio choice strategies. Table 6 allows for a comparison across different benchmark portfolio choice strategies in the presence of the capital gain tax. The table computes the certainty equivalent wealth loss of each benchmark portfolio strategy relative to the $1 / \mathrm{N}$ strategy when both pay capital gain taxes. In both tables, a negative quantity denotes a wealth loss. The values in parenthesis in Table 6 are p-values from 1,000 bootstraps under the null hypothesis that the certainty equivalent gain is non-positive.

From Table 5, the cost of taxation is large across all data sets and all trading strategies with certainty equivalent wealth losses ranging from $-10.72 \%$ to $-20.99 \%$. Consistent with its large trading volume, the PPN strategy generates the largest cost of taxation for most data sets and trading fees. The relation between welfare costs from introducing taxation and transaction costs is driven through two main channels. First, in general, welfare losses tend to increase with the level of transaction costs. Due to the curvature of the utility function, additional tax costs have stronger welfare effects when investors already face transaction costs. Second, the payment of taxes reduces the size of the overall portfolio and thereby the amount of transaction costs paid. Our results for the $\mathrm{BH}$ and the PPN strategy show that these two counteracting effects can result in welfare effects from introducing taxation being both increasing and decreasing in the level of the transaction cost.

We now ask, from an after-tax perspective, how each trading strategy performs relative to the $1 / \mathrm{N}$ strategy. From Panel A of Table 6, the results, under no transaction costs, show that accounting for taxation results in PPN no longer systematically dominating 1/N. Instead, PPN only outperforms $1 / \mathrm{N}$ for the CRSP data set. As transaction costs increase, $1 / \mathrm{N}$ starts dominating PPN. Also, the buy-and-hold strategy (BH), given its low 
trading volume from Panel $\mathrm{B}$ of Table 3 , has an improved performance relative to $1 / \mathrm{N}$. Our results for the BH strategy suggest that for reasonable levels of transaction costs, it is important to reduce trading costs and defer capital gains tax payments. Whereas the BH strategy solely focuses on this motive and ignores risk-versus-return considerations, the other portfolio strategies solely focus on risk-versus-return or diversification considerations without considering tax or transaction costs. Therefore, we turn to studying whether portfolio strategies that trade these considerations off against each other can perform better in Section 4 .

Our results in Tables 5 and 6 indicate that the tax treatment of gains in the final trade to liquidate the portfolio has a small impact on the relative performance of the portfolio strategies. Thus, we only report results for the case when capital gains are taxed on the final liquidation date throughout. Results for the case where capital gains on the final trade date are forgiven are similar and are available in our online appendix.

\section{Benefits of Heuristic Tax Trading Rules}

The previous section, especially Table 5, highlighted that taxation can have a large impact on an investor who attempts to implement a portfolio strategy by naïvely ignoring the effect of capital gain taxation. Computing optimal portfolios in the presence of realization-based capital gain taxation is complex because profits are only taxed when a trading position is closed. As a consequence, historical purchase prices and quantities have to be tracked, resulting in the number of state variables growing linearly and computation time growing exponentially in the number of assets considered. Solving for optimal portfolio decisions efficiently becomes numerically intractable for a large number of assets and trading periods. Gallmeyer, Kaniel, and Tompaidis (2006) describe some of the computational issues related to just a two stock capital gain tax portfolio choice problem. Already for their two stock case, they have to employ parallel computing techniques to solve a lifetime portfolio choice problem. However, portfolios consisting of only few assets are typically far from being realistic.

Additionally, our results from the previous section suggest that tax-effects have strong 
0 Basis Point Transaction Cost

Panel A: No taxation at end Panel B: Taxation at end

\begin{tabular}{lrrrrrrrr} 
Data & $1 / \mathrm{N}$ & $\mathrm{MV}$ & $\mathrm{BH}$ & $\mathrm{PPN}$ & $1 / \mathrm{N}$ & $\mathrm{MV}$ & $\mathrm{BH}$ & $\mathrm{PPN}$ \\
\hline \hline FFMF & -10.72 & -15.01 & -10.86 & -11.74 & -11.52 & -15.30 & -11.70 & -12.33 \\
INMF & -17.84 & -18.48 & -17.95 & -19.02 & -19.98 & -19.61 & -20.00 & -20.59 \\
CRSP & -13.27 & -13.67 & -12.58 & -15.58 & -15.88 & -16.30 & -14.88 & -17.38 \\
\hline \hline
\end{tabular}

50 Basis Point Transaction Cost

Panel A: No taxation at end Panel B: Taxation at end

\begin{tabular}{lrrrrrrrr} 
Data & $1 / \mathrm{N}$ & $\mathrm{MV}$ & $\mathrm{BH}$ & $\mathrm{PPN}$ & $1 / \mathrm{N}$ & $\mathrm{MV}$ & $\mathrm{BH}$ & $\mathrm{PPN}$ \\
\hline \hline FFMF & -10.77 & -14.97 & -10.82 & -11.91 & -11.58 & -15.27 & -11.67 & -12.52 \\
INMF & -18.09 & -18.63 & -17.88 & -19.34 & -20.25 & -19.79 & -19.94 & -20.88 \\
CRSP & -13.61 & -14.01 & -12.54 & -16.21 & -16.27 & -16.71 & -14.86 & -18.04 \\
\hline \hline
\end{tabular}

100 Basis Point Transaction Cost

Panel A: No taxation at end Panel B: Taxation at end

\begin{tabular}{lrrrrrrrr} 
Data & $1 / \mathrm{N}$ & $\mathrm{MV}$ & $\mathrm{BH}$ & $\mathrm{PPN}$ & $1 / \mathrm{N}$ & $\mathrm{MV}$ & $\mathrm{BH}$ & $\mathrm{PPN}$ \\
\hline \hline FFMF & -10.79 & -14.93 & -10.79 & -12.05 & -11.60 & -15.24 & -11.64 & -12.67 \\
INMF & -18.21 & -18.69 & -17.80 & -19.45 & -20.37 & -19.86 & -19.88 & -20.99 \\
CRSP & -13.84 & -14.23 & -12.50 & -16.34 & -16.55 & -16.94 & -14.83 & -18.22 \\
\hline \hline
\end{tabular}

Table 5: Certainty Equivalent Wealth Loss under Taxation. This table reports the percentage loss in initial wealth an investor would accept to trade under a no-tax regime under each data set. Panel A shows results when unrealized capital gains are not taxed at the end of the investment horizon and Panel B illustrates when they are. 
0 Basis Point Transaction Cost

Panel A: No taxation at end Panel B: Taxation at end

\begin{tabular}{llrrrrr} 
Data & MV & BH & PPN & MV & BH & PPN \\
\hline \hline FFMF & -10.53 & 1.32 & -0.49 & -10.03 & 1.27 & -0.26 \\
& $(0.85)$ & $(0.25)$ & $(0.57)$ & $(0.84)$ & $(0.25)$ & $(0.50)$ \\
INMF & -19.59 & -1.78 & -0.35 & -18.57 & -1.67 & 0.34 \\
& $(0.92)$ & $(0.66)$ & $(0.46)$ & $(0.92)$ & $(0.67)$ & $(0.38)$ \\
CRSP & -1.06 & -10.41 & 0.47 & -1.10 & -10.06 & 1.38 \\
& $(0.70)$ & $(1.00)$ & $(0.35)$ & $(0.71)$ & $(1.00)$ & $(0.00)$ \\
\hline \hline
\end{tabular}

50 Basis Point Transaction Cost

\begin{tabular}{llrrrrr}
\hline \hline FFMF & -9.82 & 2.18 & -5.67 & -9.32 & 2.13 & -5.47 \\
& $(0.85)$ & $(0.19)$ & $(0.94)$ & $(0.84)$ & $(0.19)$ & $(0.95)$ \\
INMF & -19.36 & 0.53 & -4.23 & -18.35 & 0.66 & -3.51 \\
& $(0.92)$ & $(0.48)$ & $(0.90)$ & $(0.92)$ & $(0.46)$ & $(0.88)$ \\
CRSP & -1.41 & -7.60 & -6.68 & -1.48 & -7.19 & -5.83 \\
& $(0.75)$ & $(1.00)$ & $(0.99)$ & $(0.76)$ & $(1.00)$ & $(1.00)$ \\
\hline \hline
\end{tabular}

100 Basis Point Transaction Cost

\begin{tabular}{llrrrrr}
\hline \hline FFMF & -9.14 & 3.01 & -10.59 & -8.63 & 2.95 & -10.41 \\
& $(0.85)$ & $(0.16)$ & $(0.94)$ & $(0.84)$ & $(0.15)$ & $(0.94)$ \\
INMF & -19.17 & 2.74 & -7.90 & -18.18 & 2.85 & -7.22 \\
& $(0.92)$ & $(0.28)$ & $(0.92)$ & $(0.92)$ & $(0.22)$ & $(0.94)$ \\
CRSP & -1.75 & -4.82 & -13.10 & -1.78 & -4.35 & -12.30 \\
& $(0.80)$ & $(1.00)$ & $(1.00)$ & $(0.81)$ & $(1.00)$ & $(1.00)$ \\
\hline \hline
\end{tabular}

Table 6: Certainty Equivalent Wealth Gain/Loss Relative to the 1/N Strategy. This table reports the certainty equivalent gain/loss in percent of initial wealth a particular portfolio choice strategy earns compared to the $1 / \mathrm{N}$ trading strategy. The values in parenthesis are p-values from 1,000 bootstraps under the null hypothesis that the certainty equivalent gain is non-positive. Panel A shows results when unrealized capital gains are not taxed at the end of the investment horizon Panel B illustrates when they are. 
welfare implications. Thus, we develop a set of heuristic tax trading strategies, or overlays, that are meant to augment the no tax optimal portfolio choice by tax-optimizing the portfolios in an economically motivated manner. We ask how much performance improves out-of-sample with these modifications compared to the non-modified portfolio choice strategies.

\subsection{Heuristic Tax Trading Strategies Considered}

Our choice of heuristic tax trading strategies is driven by intuition from the capital gain tax portfolio choice literature such as Constantinides (1983), Dammon, Spatt, and Zhang (2001b), and Gallmeyer, Kaniel, and Tompaidis (2006). In this literature, an investor always trades off rebalancing a portfolio for risk-return incentives against the tax costs of rebalancing.

Our heuristic modifications to the portfolio choice strategies differ in how they choose to rebalance securities with embedded capital gains. The heuristic strategies considered are as follows:

1. Never Realize Gains Strategy (NRG). Under the NRG strategy, the investor never realizes any capital gains before the end of the investment horizon. This strategy allows for a strong capital gain lock-in effect in that no capital gain taxes are ever paid on the portfolio until possibly the end of the investment horizon. Securities that appreciate in value are not rebalanced to their no-tax benchmark portfolio weights. Once losses are realized, these securities can be rebalanced. The method used to rebalance, described below, is assumed to be the same for all the heuristic strategies. Dividends paid in the NRG strategy, as well the other heuristic strategies, are used to rebalance the portfolio weights as described below. In contrast, the $\mathrm{BH}$ strategy always reinvests dividends back into the security that paid them.

2. Only Realize Gains when Endowed with Losses (ORL). In contrast to the NRG strategy, the ORL strategy allows for rebalancing positions with embedded capital gains, but only if there are existing capital losses, either current or unused 
from the past in the form of a tax loss carry forward. When the capital loss available is not large enough to cover all the capital gains necessary for rebalancing, we assume that the investor first realizes the gains on those positions with the highest deviation from the benchmark portfolio weight. We also studied a modification of this strategy where gains are first realized in portfolio positions where the level of unrealized gains per unit of equity is smallest.

3. Portfolio Weight Proportional Deviation of $X \%$ (PDX). Under the PDX strategy, each portfolio weight can deviate away from its benchmark portfolio weight by a maximum of $X$ percent. For example, if the benchmark portfolio weight in stock $i$ is $\hat{w}_{i}$, the portfolio weight of stock $i, w_{i}$, must always be contained in the set $w_{i} \in\left[(1-X) \hat{w}_{i},(1+X) \hat{w}_{i}\right]$. Results are presented for $X=10 \%$; other choices for $X$ are available in our online appendix.

\section{Portfolio Weight Absolute Deviation of $X$ Percentage Points (ADX).} Under the ADX strategy, we restrict the sum of portfolio weight deviations from their benchmark by $X$ percentage points, equally distributed among the individual assets. Each portfolio weight can deviate away from its benchmark portfolio weight by a maximum of $X / N$ percentage points where $N$ is the total number of stocks in the portfolio. For example, if the benchmark portfolio weight in stock $i$ is $\hat{w}_{i}>$ 0 , the portfolio weight of stock $i, w_{i}$, must always be contained in the set $w_{i} \in$ $\left[\max \left\{0, \hat{w}_{i}-\frac{X}{N}\right\}, \min \left\{\hat{w}_{i}+\frac{X}{N}, 1\right\}\right]$. The ADX and the PDX strategies behave similarly when portfolio weights are close to $1 / \mathrm{N}$. When portfolio weights deviate from $1 / \mathrm{N}$, small portfolio weights are allowed to move more before rebalancing under the ADX strategy than the PDX strategy. Results are presented when $X=1 \%, 10 \%, 25 \%$, and $50 \%$.

\section{Portfolio Weight Deviation as a Multiple $X$ of Unrealized Gains (GX).} Under the GX strategy, the investor allows for a deviation from his benchmark portfolio weight which is a multiple $X$ of the investor's average level of unrealized capital gains per dollar held in that position. If the investor is not endowed with 
unrealized gains in some portfolio position, any deviation in that position is accepted to avoid tax-payments on other positions. This heuristic strategy is meant to make rebalancing a function of embedded capital gains. For large embedded capital gains, a larger portfolio weight deviation is allowed. Results are presented when $X=0.1$ and 0.2 .

All of these heuristic trading strategies, summarized in Table 7 , are applied to the $1 / \mathrm{N}$, and PPN trading strategies ${ }^{19}$ Since the buy-and-hold strategy BH does not involve an optimal set of portfolio weights, the tax heuristics cannot be applied to this strategy. Instead, the BH strategy should simply be viewed as an extreme form of a tax heuristic that solely focuses on tax considerations, but entirely ignores risk-versus-return considerations.

Under all heuristic portfolio trading strategies, the investor only realizes losses when the benefit of offsetting capital gains dominates the transaction cost paid. This implies that after tax-loss selling and after adjusting portfolio weights to fulfill the rebalancing constraints outlined above, the portfolio weights no longer necessarily sum to one, requiring an adjustment to some of the weights. Our method of rebalancing the portfolio so that all funds are still invested is as follows:

1. Losses are realized only when the immediate benefit outweighs the transaction costs paid.

2. For all securities where the entering equity exposure from previous trading is smaller than the minimum or larger than the maximum equity exposure based on the above heuristic strategies, the portfolio weights are set to the minimum or maximum equity exposure and are no longer changed to make sure the heuristic trading strategy is followed.

3. The difference between one and the current sum of portfolio weights is computed.

\footnotetext{
${ }^{19}$ For space considerations, we do not present results for the other benchmark strategies here. While they show significant welfare gains from applying the tax-optimizing heuristics, their poor performance relative to $1 / \mathrm{N}$, as seen in Table 6 , results in the tax-heuristic-modified versions of these strategies still being outperformed by $1 / \mathrm{N}$. We also restrict our presentation of results to the PDX, the ADX and the GX strategies in this manuscript. The NRG and the ORL strategy are typically not able to systematically improve out-of-sample performance. Therefore, results for these strategies are not presented here. These results are available in our online appendix.
} 
The securities that can be feasibly traded without violating a constraint or triggering a tax payment are identified. The portfolio weights of these securities are adjusted such that the maximum absolute deviation of the heuristic portfolio weights from their corresponding benchmark portfolio weights is minimized subject to the requirement that all portfolio weights sum to one.

A simple example illustrates how this rebalancing works. Consider a portfolio with four securities and the benchmark portfolio strategy is $1 / \mathrm{N}$. Assume the heuristic tax trading strategy AD20 is implemented in a setting with no transaction costs and four stocks with current equity weights of $(0.35,0.27,0.2,0.18)$. The first two positions have unrealized capital gains. The last two positions have unrealized capital losses. The portfolio rebalancing would proceed as follows:

1. First, the last two positions are tax loss sold, giving the portfolio weights $(0.35,0.27,0,0)$.

2. According to the AD20 strategy, the maximum and minimum portfolio weights for all stocks are $0.25+0.05=0.3$ and $0.25-0.05=0.2$, respectively. The first portfolio weight is set to the maximum level. The third and fourth portfolio weighs are set to the minimum level. The second portfolio is unchanged. The resulting vector of portfolio weights is then $(0.3,0.27,0.2,0.2)$. The first portfolio weight cannot be increased, while the third and fourth portfolio weights cannot be decreased.

3. As the sum of the portfolio weights is now 0.97 , there is still a portfolio weight of 0.03 to be distributed. Securities three and four can be moved closer to the benchmark strategy with no tax costs. Minimizing the maximum absolute deviation of these two heuristic portfolio weights from the benchmark portfolio weights adds 0.015 to the weights of both securities. The resulting heuristic portfolio becomes $(0.3,0.27,0.215,0.215)$.

\subsection{Results}

With these heuristic modifications to our portfolio strategies, we ask how each performs under two different metrics. First, do the heuristic modifications lead to certainty 
The investor only realizes gains when endowed with tax loss carryORL forward. Positions with the highest deviation from the benchmark portfolio weight are realized first.

The investor accepts a deviation from the benchmark portfolio weights PDX that does not exceed a multiple of $\mathrm{X}$ percentage points, $w_{i} \in[(1-$ $\left.X) \hat{w}_{i},(1+X) \hat{w}_{i}\right]$.

The investor accepts a deviation from the benchmark portfolio weights that does not exceed $\mathrm{X}$ divided by the number of stocks considered in percentage points, $w_{i} \in\left[\max \left\{0, \hat{w}_{i}-\frac{X}{N}\right\}, \min \left\{\hat{w}_{i}+\frac{X}{N}, 1\right\}\right]$.

The investor accepts a deviation from each benchmark portfolio weight which is a constant multiple $\mathrm{X}$ of the average unrealized capital gain per dollar held in that position.

\section{Table 7: Heuristic Trading Strategies.}

equivalent improvements relative to the non-tax-optimized strategies? In other words, do the tax heuristic strategy modifications actually add value? Second, if the tax heuristics do add value, which combination of trading strategy plus tax heuristic leads to the greatest certainty equivalent improvement?

Starting with the first metric, Table 8 summarizes how the tax heuristic modifications impact the original 1/N and PPN trading strategies under 0, 50, and 100 basis point fees. In these tables, positive certainty equivalents imply that the tax heuristic modification adds value over the original trading strategy.

Under no fees, Table 8 shows that the tax heuristic modifications generally improve investor welfare for the $1 / \mathrm{N}$ strategy. In particular, the portfolio weight absolute deviation $\mathrm{AD}$ heuristics generally improve the $1 / \mathrm{N}$ strategy's performance. The improvement in the $1 / \mathrm{N}$ strategy is as large as $2.07 \%$ of wealth in the absence of brokerage fees. Similarly, the parametric portfolio PPN strategy is generally improved.

Introducing fees generally improves the performance of the tax heuristics as can be seen in Table 8. Since the tax heuristics considered also reduce trading, we should 


\begin{tabular}{|c|c|c|c|c|c|c|c|c|c|}
\hline Brokerage Fee & Model & Data & PD10 & $\mathrm{AD} 1$ & AD10 & $\mathrm{AD} 25$ & AD50 & G0.1 & G0.2 \\
\hline \multirow{12}{*}{0 Basis Points } & \multirow{6}{*}{$1 / \mathrm{N}$} & FFMF & 1.16 & 0.21 & 1.16 & 1.38 & 1.16 & 0.43 & 0.39 \\
\hline & & & $(0.17)$ & $(0.18)$ & $(0.17)$ & $(0.23)$ & $(0.27)$ & $(0.26)$ & $(0.29)$ \\
\hline & & INMF & 1.46 & 0.34 & 1.46 & 1.03 & 2.07 & 0.86 & 0.73 \\
\hline & & & $(0.16)$ & $(0.00)$ & $(0.16)$ & $(0.37)$ & $(0.30)$ & $(0.27)$ & $(0.36)$ \\
\hline & & CRSP & 0.11 & 0.33 & 0.11 & 0.66 & -2.31 & -2.46 & -5.32 \\
\hline & & & $(0.19)$ & $(0.01)$ & $(0.19)$ & $(0.06)$ & $(0.97)$ & $(0.99)$ & $(0.99)$ \\
\hline & \multirow{6}{*}{ PPN } & FFMF & 0.08 & 0.18 & 0.34 & 1.40 & 2.30 & -0.14 & -0.22 \\
\hline & & & $(0.23)$ & $(0.05)$ & $(0.03)$ & $(0.17)$ & $(0.23)$ & $(0.65)$ & $(0.67)$ \\
\hline & & INMF & 1.29 & 0.44 & 1.50 & 1.47 & 0.29 & 0.67 & 0.88 \\
\hline & & & $(0.01)$ & $(0.00)$ & $(0.04)$ & $(0.05)$ & $(0.51)$ & $(0.37)$ & $(0.41)$ \\
\hline & & CRSP & 2.30 & 2.24 & 2.65 & 1.33 & 1.28 & 0.77 & -1.62 \\
\hline & & & $(0.00)$ & $(0.00)$ & $(0.00)$ & $(0.04)$ & $(0.07)$ & $(0.03)$ & $(1.00)$ \\
\hline \multirow{12}{*}{50 Basis Points } & \multirow{6}{*}{$1 / \mathrm{N}$} & FFMF & 1.87 & 0.56 & 1.87 & 2.18 & 2.03 & 1.08 & 1.11 \\
\hline & & & $(0.21)$ & $(0.22)$ & $(0.21)$ & $(0.24)$ & $(0.25)$ & $(0.21)$ & $(0.24)$ \\
\hline & & INMF & 2.98 & 0.94 & 2.98 & 3.04 & 4.31 & 2.52 & 2.75 \\
\hline & & & $(0.04)$ & $(0.00)$ & $(0.04)$ & $(0.21)$ & $(0.21)$ & $(0.10)$ & $(0.18)$ \\
\hline & & CRSP & 2.20 & 1.31 & 2.20 & 3.25 & 0.52 & 0.12 & -2.58 \\
\hline & & & $(0.01)$ & $(0.00)$ & $(0.01)$ & $(0.02)$ & $(0.04)$ & $(0.29)$ & $(0.99)$ \\
\hline & \multirow{6}{*}{$\mathrm{PPN}$} & FFMF & 3.13 & 2.14 & 3.74 & 6.19 & 8.06 & 2.53 & 3.15 \\
\hline & & & $(0.11)$ & $(0.12)$ & $(0.10)$ & $(0.13)$ & $(0.14)$ & $(0.07)$ & $(0.07)$ \\
\hline & & INMF & 4.24 & 2.16 & 4.85 & 6.27 & 6.05 & 3.18 & 4.65 \\
\hline & & & $(0.03)$ & $(0.02)$ & $(0.05)$ & $(0.04)$ & $(0.06)$ & $(0.12)$ & $(0.20)$ \\
\hline & & CRSP & 6.24 & 6.39 & 7.44 & 8.27 & 9.94 & 7.04 & 6.50 \\
\hline & & & $(0.00)$ & $(0.00)$ & $(0.00)$ & $(0.00)$ & $(0.00)$ & $(0.00)$ & $(0.00)$ \\
\hline \multirow{12}{*}{100 Basis Points } & \multirow{6}{*}{$1 / \mathrm{N}$} & FFMF & 2.57 & 0.92 & 2.57 & 2.97 & 2.85 & 1.71 & 1.78 \\
\hline & & & $(0.23)$ & $(0.22)$ & $(0.23)$ & $(0.22)$ & $(0.18)$ & $(0.19)$ & $(0.21)$ \\
\hline & & INMF & 4.44 & 1.55 & 4.44 & 4.91 & 6.41 & 4.04 & 4.61 \\
\hline & & & $(0.02)$ & $(0.00)$ & $(0.02)$ & $(0.10)$ & $(0.16)$ & $(0.06)$ & $(0.11)$ \\
\hline & & CRSP & 4.27 & 2.50 & 4.27 & 5.81 & 3.32 & 2.64 & 0.11 \\
\hline & & & $(0.02)$ & $(0.01)$ & $(0.02)$ & $(0.02)$ & $(0.01)$ & $(0.01)$ & $(0.33)$ \\
\hline & \multirow{6}{*}{ PPN } & FFMF & 6.26 & 4.47 & 7.25 & 11.19 & 14.13 & 5.29 & 6.63 \\
\hline & & & $(0.10)$ & $(0.11)$ & $(0.09)$ & $(0.11)$ & $(0.11)$ & $(0.07)$ & $(0.07)$ \\
\hline & & INMF & 7.30 & 4.15 & 8.32 & 11.22 & 11.96 & 5.74 & 8.47 \\
\hline & & & $(0.05)$ & $(0.03)$ & $(0.07)$ & $(0.05)$ & $(0.06)$ & $(0.09)$ & $(0.13)$ \\
\hline & & CRSP & 10.75 & 11.51 & 12.48 & 15.68 & 18.92 & 13.77 & 14.99 \\
\hline & & & $(0.00)$ & $(0.00)$ & $(0.00)$ & $(0.00)$ & $(0.00)$ & $(0.00)$ & $(0.00)$ \\
\hline
\end{tabular}

Table 8: Certainty Equivalent Wealth Gain/Loss of Each Heuristic Tax Trading Strategy Relative to the Non-Tax-Optimized Strategy for $1 / \mathrm{N}$ and PPN. This table reports the certainty equivalent gain/loss in percent of initial wealth a particular heuristic tax trading strategy earns relative to the non-tax-optimized strategy under each data set. The values in parenthesis are p-values from 1,000 bootstraps for the null hypothesis that the certainty equivalent gain is non-positive. 
expect to see an improvement in portfolio performance once brokerage fees are imposed. Turning to the 50 basis point fee case, the portfolio weight absolute deviation AD heuristic improves even more for the $1 / \mathrm{N}$ strategy. For example, the welfare gains more than triple for the INMF data set rising above $4.3 \%$ in some cases. These welfare effects tend to be even bigger for the PPN strategy. When brokerage fees jump to 100 basis points, all tax heuristics improve portfolio performance.

Having established that the tax heuristics can improve each of the trading strategies, which combination of trading strategy plus tax heuristic leads to the greatest welfare increase for an investor? We answer this by comparing the PPN strategy for a particular tax heuristic to the $1 / \mathrm{N}$ trading strategy with the same tax heuristic imposed. We also compare the unmodified buy-and-hold strategy to the $1 / \mathrm{N}$ strategy with all tax heuristics. Table 9 reports these certainty equivalents for brokerage fees of 0, 50, and 100 basis points respectively.

At a 0 basis point fee, Table 9 shows that the BH strategy generally does not dominate the $1 / \mathrm{N}$ strategy, suggesting that an optimal portfolio strategy trades risk-versus-return considerations off against tax concerns. Additionally, the PPN strategy with a tax overlay still dominates $1 / \mathrm{N}$ for some data sets.

However, this changes once one turns to a non-zero transaction cost setting. At a 50 basis point fee, the PPN strategy is largely dominated by $1 / \mathrm{N}$. However, the PPN strategy augmented with the AD50 tax heuristic still dominates $1 / \mathrm{N}$ for the CRSP data set. Turning to the 100 basis point fee, the PPN strategy with the AD50 tax heuristic continues to dominate the $1 / \mathrm{N}$ strategy under the same heuristic for the CRSP data set. This improvement in the PPN strategy is driven by the tax heuristic imposing a much lower trading volume as can be seen in Table 10. The BM column in these tables represents the no-tax trading volume benchmark. As can be seen, the tax heuristics in general greatly reduce trading volume contributing to the increase in welfare.

Overall, overlaying a tax heuristic on an existing trading strategy can improve portfolio performance as measured by the investor's certainty equivalent. Once brokerage fees 


\begin{tabular}{|c|c|c|c|c|c|c|c|c|c|}
\hline Brokerage Fee & Model & Data & PD10 & $\mathrm{AD} 1$ & AD10 & AD25 & AD50 & G0.1 & G0.2 \\
\hline \multirow{12}{*}{0 Basis Points } & \multirow{6}{*}{$\mathrm{BH}$} & \multirow[t]{2}{*}{ FFMF } & 0.10 & 1.06 & 0.10 & -0.11 & 0.10 & 0.83 & 0.87 \\
\hline & & & $(0.49)$ & $(0.26)$ & $(0.49)$ & $(0.59)$ & $(0.46)$ & $(0.27)$ & $(0.26)$ \\
\hline & & \multirow[t]{2}{*}{ INMF } & -3.08 & -2.00 & -3.08 & -2.68 & -3.66 & -2.51 & -2.38 \\
\hline & & & $(0.79)$ & $(0.71)$ & $(0.79)$ & $(0.69)$ & $(0.75)$ & $(0.74)$ & $(0.72)$ \\
\hline & & \multirow[t]{2}{*}{ CRSP } & -10.15 & -10.35 & -10.15 & -10.65 & -7.93 & -7.79 & -5.00 \\
\hline & & & $(1.00)$ & $(1.00)$ & $(1.00)$ & $(1.00)$ & $(1.00)$ & $(1.00)$ & $(0.99)$ \\
\hline & \multirow{6}{*}{$\mathrm{PPN}$} & \multirow[t]{2}{*}{ FFMF } & -1.33 & -0.29 & -1.08 & -0.24 & 0.86 & -0.83 & -0.88 \\
\hline & & & $(0.83)$ & $(0.50)$ & $(0.79)$ & $(0.48)$ & $(0.30)$ & $(0.83)$ & $(0.82)$ \\
\hline & & \multirow[t]{2}{*}{ INMF } & 0.17 & 0.44 & 0.38 & 0.76 & -1.41 & 0.15 & 0.49 \\
\hline & & & $(0.38)$ & $(0.35)$ & $(0.35)$ & $(0.30)$ & $(0.61)$ & $(0.38)$ & $(0.29)$ \\
\hline & & \multirow[t]{2}{*}{ CRSP } & 3.60 & 3.31 & 3.95 & 2.05 & 5.12 & 4.73 & 5.35 \\
\hline & & & $(0.00)$ & $(0.03)$ & $(0.00)$ & $(0.00)$ & $(0.01)$ & $(0.00)$ & $(0.01)$ \\
\hline \multirow{12}{*}{50 Basis Points } & \multirow{6}{*}{$\mathrm{BH}$} & \multirow[t]{2}{*}{ FFMF } & 0.25 & 1.56 & 0.25 & -0.05 & 0.10 & 1.04 & 1.01 \\
\hline & & & $(0.38)$ & $(0.20)$ & $(0.38)$ & $(0.57)$ & $(0.46)$ & $(0.20)$ & $(0.20)$ \\
\hline & & \multirow[t]{2}{*}{ INMF } & -2.25 & -0.28 & -2.25 & -2.31 & -3.50 & -1.81 & -2.03 \\
\hline & & & $(0.71)$ & $(0.54)$ & $(0.71)$ & $(0.67)$ & $(0.74)$ & $(0.69)$ & $(0.71)$ \\
\hline & & \multirow[t]{2}{*}{ CRSP } & -9.19 & -8.39 & -9.19 & -10.11 & -7.67 & -7.30 & -4.73 \\
\hline & & & $(1.00)$ & $(1.00)$ & $(1.00)$ & $(1.00)$ & $(1.00)$ & $(1.00)$ & $(0.99)$ \\
\hline & \multirow{6}{*}{$\mathrm{PPN}$} & \multirow[t]{2}{*}{ FFMF } & -4.30 & -3.98 & -3.73 & -1.76 & 0.13 & -4.11 & -3.55 \\
\hline & & & $(0.94)$ & $(0.95)$ & $(0.94)$ & $(0.94)$ & $(0.35)$ & $(0.94)$ & $(0.93)$ \\
\hline & & \multirow[t]{2}{*}{ INMF } & -2.32 & -2.35 & -1.76 & -0.49 & -1.91 & -2.89 & -1.73 \\
\hline & & & $(0.83)$ & $(0.82)$ & $(0.81)$ & $(0.53)$ & $(0.64)$ & $(0.94)$ & $(0.93)$ \\
\hline & & \multirow[t]{2}{*}{ CRSP } & -2.11 & -1.11 & -1.01 & -1.25 & 3.00 & 0.68 & 2.94 \\
\hline & & & $(0.94)$ & $(0.78)$ & $(0.84)$ & $(0.85)$ & $(0.02)$ & $(0.06)$ & $(0.01)$ \\
\hline \multirow{12}{*}{100 Basis Points } & \multirow{6}{*}{$\mathrm{BH}$} & \multirow[t]{2}{*}{ FFMF } & 0.38 & 2.02 & 0.38 & -0.01 & 0.10 & 1.23 & 1.15 \\
\hline & & & $(0.28)$ & $(0.16)$ & $(0.28)$ & $(0.55)$ & $(0.46)$ & $(0.14)$ & $(0.14)$ \\
\hline & & \multirow[t]{2}{*}{ INMF } & -1.52 & 1.28 & -1.52 & -1.96 & -3.34 & -1.14 & -1.68 \\
\hline & & & $(0.65)$ & $(0.41)$ & $(0.65)$ & $(0.64)$ & $(0.74)$ & $(0.66)$ & $(0.71)$ \\
\hline & & \multirow[t]{2}{*}{ CRSP } & -8.27 & -6.68 & -8.27 & -9.61 & -7.43 & -6.81 & -4.46 \\
\hline & & & $(1.00)$ & $(1.00)$ & $(1.00)$ & $(1.00)$ & $(1.00)$ & $(1.00)$ & $(0.99)$ \\
\hline & \multirow{6}{*}{ PPN } & \multirow[t]{2}{*}{ FFMF } & -7.19 & -7.26 & -6.32 & -3.26 & -0.59 & -7.26 & -6.15 \\
\hline & & & $(0.94)$ & $(0.96)$ & $(0.94)$ & $(0.96)$ & $(0.90)$ & $(0.93)$ & $(0.94)$ \\
\hline & & \multirow[t]{2}{*}{ INMF } & -4.69 & -4.84 & -3.78 & -1.64 & -2.38 & -5.71 & -3.80 \\
\hline & & & $(0.92)$ & $(0.91)$ & $(0.92)$ & $(0.79)$ & $(0.67)$ & $(0.96)$ & $(0.98)$ \\
\hline & & CRSP & -6.86 & -4.60 & -5.40 & -4.12 & 0.94 & -2.79 & 0.73 \\
\hline & & & $(0.99)$ & $(0.95)$ & $(0.99)$ & $(0.96)$ & $(0.19)$ & $(0.97)$ & $(0.21)$ \\
\hline
\end{tabular}

Table 9: Certainty Equivalent Wealth Gain/Loss of Each Heuristic Tax Trading Strategy Relative to the Corresponding Heuristic 1/N Strategy for BH and PPN. This table reports the certainty equivalent gain/loss in percent of initial wealth a particular heuristic tax trading strategy earns relative to the corresponding heuristic $1 / \mathrm{N}$ strategy under each data set. The values in parenthesis are p-values from 1,000 bootstraps under the null hypothesis that the certainty equivalent gain is nonpositive. 


\begin{tabular}{|c|c|c|c|c|c|c|c|c|c|c|}
\hline Brokerage Fee & Model & Data & $\mathrm{BM}$ & PD10 & AD1 & AD10 & AD25 & AD 50 & G0.1 & G0.2 \\
\hline \multirow{6}{*}{0 Basis Points } & \multirow{3}{*}{$1 / \mathrm{N}$} & FFMF & 2.57 & 1.06 & 2.10 & 1.06 & 0.78 & 0.58 & 1.08 & 0.87 \\
\hline & & INMF & 4.97 & 2.18 & 4.41 & 2.18 & 1.34 & 0.93 & 1.90 & 1.18 \\
\hline & & CRSP & 7.61 & 3.78 & 6.82 & 3.78 & 2.37 & 1.67 & 1.70 & 1.22 \\
\hline & \multirow{3}{*}{$\mathrm{PPN}$} & FFMF & 13.64 & 9.11 & 12.97 & 9.06 & 5.69 & 3.13 & 9.70 & 7.56 \\
\hline & & INMF & 11.51 & 7.29 & 10.81 & 7.05 & 4.22 & 2.19 & 7.72 & 5.42 \\
\hline & & CRSP & 20.89 & 15.00 & 20.12 & 15.52 & 10.89 & 6.87 & 9.42 & 4.97 \\
\hline \multirow{6}{*}{50 Basis Points } & \multirow{3}{*}{$1 / N$} & FFMF & 2.18 & 0.84 & 1.70 & 0.84 & 0.67 & 0.56 & 1.01 & 0.87 \\
\hline & & INMF & 4.33 & 1.92 & 3.78 & 1.92 & 1.18 & 0.86 & 1.74 & 1.14 \\
\hline & & CRSP & 6.58 & 3.14 & 5.84 & 3.14 & 2.04 & 1.46 & 1.54 & 1.10 \\
\hline & \multirow{3}{*}{$\mathrm{PPN}$} & FFMF & 12.82 & 8.32 & 12.18 & 8.33 & 5.18 & 2.80 & 8.94 & 7.05 \\
\hline & & INMF & 10.51 & 6.50 & 9.84 & 6.28 & 3.79 & 1.98 & 7.12 & 5.09 \\
\hline & & CRSP & 19.07 & 13.47 & 18.36 & 13.94 & 9.58 & 5.94 & 8.68 & 4.63 \\
\hline \multirow{6}{*}{100 Basis Points } & \multirow{3}{*}{$1 / \mathrm{N}$} & FFMF & 2.08 & 0.78 & $\overline{1.59}$ & 0.78 & 0.63 & 0.55 & 0.98 & 0.87 \\
\hline & & INMF & 4.07 & 1.76 & 3.53 & 1.76 & 1.09 & 0.81 & 1.65 & 1.11 \\
\hline & & CRSP & 5.99 & 2.74 & 5.29 & 2.74 & 1.79 & 1.28 & 1.40 & 1.01 \\
\hline & \multirow{3}{*}{$\mathrm{PPN}$} & FFMF & 12.66 & 8.17 & 12.04 & 8.17 & 5.03 & 2.65 & 8.75 & 6.89 \\
\hline & & INMF & 10.14 & 6.21 & 9.47 & 6.00 & 3.60 & 1.89 & 6.85 & 4.95 \\
\hline & & CRSP & 18.16 & 12.63 & 17.51 & 13.16 & 8.94 & 5.50 & 8.15 & 4.44 \\
\hline
\end{tabular}

Table 10: Trading Volume under the Tax Heuristic Strategies. This table reports the trading volume as a percentage of wealth under the benchmark strategies and the tax heuristic strategies.

are incorporated, it is not possible to find trading strategies with overlayed tax heuristics that systematically dominate the corresponding tax optimized $1 / \mathrm{N}$ strategy. In particular, the $1 / \mathrm{N}$ strategy augmented with the ADX tax heuristic (a strategy that allows for a fixed deviation in absolute portfolio weights) performs quite well across all of the data sets. With transaction costs, Table 8 demonstrates that the wealth gain of using the ADX heuristic can be as large as $6.41 \%$. Even with a high transaction cost of 100 basis points, the BH strategy, that solely minimizes tax trading costs, is outperformed by the $1 / \mathrm{N}$ strategy augmented with an overlayed tax heuristic. That is, investment strategies should neither solely focus on diversification considerations nor tax optimization. Instead, they should trade these two incentives off against each other.

\section{Conclusion}

This paper studies the out-of-sample performance of portfolio trading strategies when an investor faces capital gain taxation and proportional transaction costs. Reconfirming 
the results of DeMiguel, Garlappi, and Uppal (2009) and Brandt, Santa-Clara, and Valkanov (2009), we show that, under no capital gain taxation and no brokerage fees, a simple $1 / \mathrm{N}$ trading strategy is not dominated out-of-sample by a variety of optimizing trading strategies with the notable exception being the parametric portfolios of Brandt, SantaClara, and Valkanov (2009). With dividend and realization-based capital gain taxes, the welfare costs of taxes are large as they are $20 \%$ of wealth in some cases. Overlaying simple tax trading heuristics on these trading strategies can improve performance. In particular, the $1 / \mathrm{N}$ trading strategy's welfare gains improve with a variety of tax trading heuristics for medium to large transaction costs. In contrast to DeMiguel, Garlappi, and Uppal (2009), trading strategies with overlayed tax trading heuristics can outperform $1 / \mathrm{N}$. A $1 / \mathrm{N}$ trading strategy with a tax heuristic that allows for a fixed deviation in absolute portfolio weights (ADX) outperforms $1 / \mathrm{N}$ alone across all data sets considered. For medium to large brokerage fees, no trading strategy can outperform a $1 / \mathrm{N}$ trading strategy augmented with a tax heuristic, not even the most tax- and transaction cost efficient buy-and-hold strategy. Our results thus show that trading strategies should trade diversification considerations off against tax considerations without solely focusing on one or the other.

\section{A. Appendix - Data Details}

Our procedure for the computation of the size and book-to-market factors for the CRSP dataset closely follows the procedure described on Kenneth French's website and in Davis, Fama, and French (2000). We use data from Compustat and CRSP. The Compustat items (identifiers in parenthesis) used are total assets (AT), total liabilities (LT), preferred stock value (PSTKRV, PSTKL, UPSTK, in that order), balance sheet deferred taxes and investment tax credits (TXDITC, otherwise zero), price per share (PRC from CRSP data base), number of shares outstanding (CSHO, otherwise SHROUT from CRSP data base), delisting code (DLSTCD from the CRSP data base), fiscal year end (FYR), an identifier that allow us to follow mergers or asset exchanges (NWPERM from CRSP data base), total return (RET from CRSP data base), ex-dividend return (RETX from 
CRSP data base), exchange code (EXCHCD from CRSP), share code (SHRCD from CRSP), SIC code (SIC), and SICCD code (SICCD from CRSP).

We compute market equity (ME) as price times shares outstanding. Price is from CRSP; shares outstanding are from Compustat (if available) or otherwise CRSP. Book equity (BE) is constructed from Compustat data. BE is the book value of stockholders' equity plus balance sheet deferred taxes and investment tax credit (if available) minus the book value of preferred stock. Depending on availability, we use the redemption, liquidation, or par value (in that order) to estimate the book value of preferred stock. Stockholders' equity is the value reported by Compustat, if it is available. If not, we measure stockholders' equity as the book value of common equity plus the par value of preferred stock, or the book value of assets minus total liabilities (in that order).

Following the procedure described in Fama and French (1997) and on Kenneth French's website, we compute the book-to-market ratio $(\mathrm{BE} / \mathrm{ME})$ at the end of June of year $t$ as book equity for the fiscal year ending in calendar year $t-1$, divided by market equity at the end of December of $t-1$. We follow the standard convention of leaving a lag of at least 6 months to ensure that the information from the firm's annual reports is publicly available. We eliminate observations from our CRSP data set where we do not have sufficient data to compute ME for December of year $t-1$ and June of year $t$ or BE for the fiscal year ending in year $t-1$. We further exclude observations having negative book equity for the fiscal year ending in year $t-1$. We eliminate assets with missing data on $\mathrm{ME}$ or $\mathrm{BE} / \mathrm{ME}$ in their time series. We allow for a lag of at least six months after the end of the fiscal year for BE/ME.

To avoid a potential survivorship bias, we do not eliminate firms that delist during the sample. We only exclude time series of assets ending without information on delisting. We further exclude assets where the delisting code DLSTCD is different from 231 (merger, where shareholders primarily receive common stocks) or 331 (asset exchanged, primarily for another class of common stock) and no information about the acquiring firm is available (i.e., where no new PERMNO (NWPERM) of the acquiring firm is available). 
For those time series where this information is available, we continue our time series with that of the new asset. To estimate portfolio weights, we use historical data from the new time series from that point in time on. Furthermore, we exclude assets where we cannot precisely determine in which way investors were compensated. That is, we exclude assets where the delisting code was not 231, 331, 233 (merger where shareholders are primarily compensated in cash), 333 (issue exchanged, primarily for cash), or beginning with 4 (liquidation). For assets whose time series end with a valid delisting code and could not be continued with another time series, for example due to liquidation, we randomly add new assets under the same criteria to our data. In case of a delisting, liquidation, or a compensation in cash, we assume that the investor's compensation is equal to the latest available market price. The investor is subject to the full immediate tax consequences of this realization. In the case when two companies in our sample merge, we randomly draw a new asset to make sure that the number of assets the investor can invest in does not decrease.

Finally, following Brandt, Santa-Clara, and Valkanov (2009), we eliminate the smallest $20 \%$ of stocks by market capitalization on January 1963. This simultaneously mitigates the issues related to using the smallest stocks reported in Bali and Cakici $(2008)$ and $\mathrm{Fu}$ (2009). We further eliminate very illiquid stocks with spreads exceeding 1\%. From the remaining stocks, we randomly draw 10 stocks to build our CRSP data set. Whenever a stock's time series ends due to reasons other than mergers, we randomly replace that stock with a new stock in our data set.

For our mutual fund datasets, we use data from the CRSP Mutual Fund Database. We clean the data, by removing funds that are not equity funds, funds that are not open to private investors, funds that are tax exempt, funds whose time series end without information on the reason for their removal, and funds with missing observations in returns. Spreads for our mutual fund dataset are regrettably not reported in the CRSP Mutual Fund Database. We therefore estimate these values based on data on existing ETFs. More specifically, we use the bid/ask spreads published on Vanguard's homepage 
(downloaded on November 11, 2013). According to this data, bid/ask spreads for industry funds are around $0.05 \%$. We therefore set the bid/ask spreads for our industry funds to $0.05 \%$. Bid/ask spreads for our style and size mutual funds tend to vary more. Specifically, bid/ask spreads for small cap funds tend to be higher than for the others. We therefore set the bid/ask spreads to those reported by Vanguard. That is, we set the bid/ask spread for the small-, mid- and large-cap funds to $0.05 \%, 0.03 \%$, and $0.03 \%$, respectively, and those for the growth and income funds to $0.02 \%$ and $0.03 \%$, respectively.

\section{B. Appendix - Treatment of Unrealized Losses with Transaction Costs}

From Constantinides (1983), an investor should realize all losses immediately when trading in a setting where no transaction costs apply and realized capital gains and losses are subject to the same tax treatment. Gallmeyer and Srivastava (2011) and Marekwica (2012) generalize this result to tax systems with limited use of losses. Once transaction costs are taken into account, the incentive to realize losses trades off against the incentive to avoid the trading costs from such trades. In particular, investors might want to avoid selling an asset to realize the losses and repurchasing that asset immediately. In general, determining the optimal loss realization strategy is of similar difficulty as determining the optimal timing of the realization of unrealized gains. This prevents us from determining the optimal loss realization strategy once trading costs are incorporated. Instead, we consider three heuristic strategies:

1. Losses are realized in all portfolio positions where present and potential future tax savings, the realized tax loss allows for, are at least as big as the present transaction costs for selling and repurchasing the assets in which a loss is realized.

2. Losses are only realized in portfolio positions where present tax savings the realized loss allows for are at least as big as the present transaction costs for selling and repurchasing the assets. In the case that more portfolio positions fulfill this condition than are required for generating the desired realized loss, to minimize the transaction costs burden from trading, only the portfolio positions with the highest 
level of unrealized loss per unit of equity are traded.

3. Losses are not realized before the end of the investment horizon.

It turns out that the two later strategies typically result in rather similar welfare results, suggesting that the exact treatment of unrealized losses might be a second-order effect once a reasonable way of dealing with unrealized losses is modeled. Most importantly, our key findings that our heuristic tax trading strategies can systematically improve outof-sample performance and that no trading strategy can systematically outperform a tax optimized $1 / \mathrm{N}$ strategy is independent of the exact treatment of unrealized losses. The first strategy tends to perform slightly worse, suggesting that it puts a somewhat too high transaction cost burden on the investor compared to the other two strategies. Our results presented are for the second strategy. Results for the first and the third strategy are available in our online appendix.

\section{References}

Balduzzi, P., Lynch, A., 1999. Transaction costs and predictability: Some utility cost calculations. Journal of Financial Economics 52 (1), 47-78.

Balduzzi, P., Lynch, A., 2000. Predictability and transaction costs: The impact on rebalancing rules and behavior. Journal of Finance 55 (5), 2285-2310.

Bali, T. G., Cakici, N., 2008. Idiosyncratic volatility and the cross section of expected returns. Journal of Financial and Quantitative Analysis 43 (1), 29-58.

Bergstresser, D., Pontiff, J., 2012. Investment taxation and portfolio performance. Journal of Public Economics 97 (1), 245-257.

Best, M., Grauer, R., 1991. On the sensitivity of mean-variance-efficient portfolios to changes in asset means: Some analytical and computational results. Review of Financial Studies 4 (2), 315-342.

Brandt, M., Santa-Clara, P., Valkanov, R., 2009. Parametric portfolio policies: Exploiting characteristics in the cross section of equity returns. Review of Financial Studies 22 (9), 3411-3447.

Chopra, V., Ziemba, W., 1993. The effect of errors in means, variances, and covariances on optimal portfolio choice. Journal of Portfolio Management 19 (2), 6-11.

Constantinides, G., 1983. Capital market equilibrium with personal tax. Econometrica 51 (3), 611-636.

Dammon, R., Spatt, C., 1996. The optimal trading and pricing of securities with asymmetric capital gains taxes and transaction costs. Review of Financial Studies 9 (3), 921-952. 
Dammon, R., Spatt, C., Zhang, H., November 2001a. Diversification and capital gains taxes with multiple risky assets. Carnegie Mellon University.

Dammon, R., Spatt, C., Zhang, H., 2001b. Optimal consumption and investment with capital gains tax. Review of Financial Studies 14 (3), 583-616.

Dammon, R., Spatt, C., Zhang, H., 2004. Optimal asset location and allocation with taxable and taxdeferred investing. Journal of Finance 59 (3), 999-1037.

Davis, J. L., Fama, E. F., French, K. R., 2000. Characteristics, covariances, and average returns: 1929 to 1997. Journal of Finance 55 (1), 389-406.

DeMiguel, V., Garlappi, L., Uppal, R., 2006. Implementation details and robustness checks: Appendix to 'Optimal versus naïve diversification: How inefficient is the $1 / \mathrm{N}$ portfolio strategy?'. London Business School and University of Texas at Austin.

DeMiguel, V., Garlappi, L., Uppal, R., 2009. Optimal versus naïve diversification: How inefficient is the 1/N portfolio strategy? Review of Financial Studies 22 (5), 1915-1953.

DeMiguel, V., Uppal, R., 2005. Portfolio investment with the exact tax basis via nonlinear programming. Management Science 51 (2), 277-290.

Ehling, P., Gallmeyer, M., Srivastava, S., Tompaidis, S., Yang, C., 2014. Portfolio choice with capital gain taxation and the limited use of losses. University of Virginia.

Fama, E. F., French, K. R., 1997. Industry costs of equity. Journal of Financial Economics 43 (2), 153-193

Fu, F., 2009. Idiosyncratic risk and the cross-section of expected stock returns. Journal of Financial Economics 91 (1), 24-37.

Gallmeyer, M., Kaniel, R., Tompaidis, S., 2006. Tax management strategies with multiple risky assets. Journal of Financial Economics 80 (2), 243-291.

Gallmeyer, M., Srivastava, S., 2011. Arbitrage and the tax code. Mathematics and Financial Economics $4(3), 183-221$.

Garlappi, L., Huang, J., 2006. Are stocks desirable in tax-deferred accounts? Journal of Public Economics $90(12), 2257-2283$.

Garlappi, L., Naik, V., Slive, J., 2001. Portfolio selection with multiple assets and capital gains taxes. University of British Columbia.

Gârleanu, N., Pedersen, L. H., 2013. Dynamic trading with predictable returns and transaction costs. Journal of Finance 68 (6), 2309-2340.

Green, R., Hollifield, B., 1992. When will mean-variance efficient portfolios be well diversified? Journal of Finance 47 (5), 1785-1809.

Huang, J., 2008. Taxable and tax-deferred investing: A tax-arbitrage approach. Review of Financial 
Studies 21 (5), 2171-2207.

Israel, R., Moskowitz, T. J., October 2012. How tax efficient are equity styles?, University of Chicago.

Jagannathan, R., Ma, T., 2003. Risk reduction in large portfolios: Why imposing the wrong constraint helps. Journal of Finance 58 (4), 1651-1684.

Jensen, B. A., Marekwica, M., 2011. Optimal portfolio choice with wash sale constraints. Journal of Economic Dynamics and Control 35 (11), 1916-1937.

Lan, C., 2014. An out-of-sample evaluation of dynamic portfolio strategies. Review of Finance, forthcoming.

Leland, H., 2001. Optimal portfolio management with transaction costs and capital gains taxes. University of California-Berkeley.

Lesmond, D., Ogden, J., Trzcinka, C., 1999. A new estimate of transaction costs. Review of Financial Studies 12 (5), 1113-1141.

Lo, A., Haugh, M., 2001a. Asset allocation and derivatives. Quantitative Finance 1 (1), 45-72.

Lo, A., Haugh, M., 2001b. Computational challenges of financial engineering. Computing in Science and Engineering 3 (3), 54-59.

Lynch, A., Tan, S., 2010. Multiple risky assets, transaction costs, and return predictability: Allocation rules and implications for U.S. investors. Journal of Financial and Quantitative Analysis 45 (4), 10151053.

Marekwica, M., 2012. Optimal tax-timing and asset allocation when tax rebates on capital losses are limited. Journal of Banking and Finance 36 (7), 2048-2063.

Markowitz, H., 1952. Portfolio selection. Journal of Finance 7 (1), 77-91.

Ravina, E., Viceira, L., Walter, I., 2011. The portfolio and financial decisions of high net worth U.S. households. Columbia University, Harvard University, and New York University.

Rogers, L., 2001. The relaxed investor and parameter uncertainty. Finance and Stochastics 5 (2), 131-154.

Sialm, C., 2009. Tax changes and asset pricing. American Economic Review 99 (4), 1356-1383. 